\title{
Genetic Diversity of Korean Rice (Oryza Sativa L.) Germplasm for Yield and Yield Related Traits for Adoption in Rice Farming System in Nigeria
}

\author{
Exonam Amegan ${ }^{1}$, Andrew Efisue ${ }^{2,}$, , Malachy Akoroda ${ }^{3}$, Afeez Shittu ${ }^{4}$, Fiot Tonegnikes ${ }^{1}$ \\ ${ }^{1}$ Life and Earth Sciences Institute, (Including Health and Agriculture), Pan African University, University of Ibadan, Ibadan, Nigeria \\ ${ }^{2}$ Department of Crop \& Soil Science, University of Port Harcourt, Port Harcourt, Rivers State, Nigeria \\ ${ }^{3}$ Department of Agronomy, Faculty of Agriculture, University of Ibadan, Ibadan, Nigeria \\ ${ }^{4}$ AfricaRice Center, IITA Ibadan, Nigeria
}

Email address:

andyefisue@yahoo.com (A. Efisue)

${ }^{*}$ Corresponding author

\section{To cite this article:}

Exonam Amegan, Andrew Efisue, Malachy Akoroda, Afeez Shittu, Fiot Tonegnikes. Genetic Diversity of Korean Rice (Oryza Sativa L.) Germplasm for Yield and Yield Related Traits for Adoption in Rice Farming System in Nigeria. International Journal of Genetics and Genomics. Vol. 8, No. 1, 2020, pp. 19-28. doi: 10.11648/j.ijgg.20200801.13

Received: December 28, 2019; Accepted: January 9, 2020; Published: January 23, 2020

\begin{abstract}
Background and objectives Assessment of genetic diversity is a prerequisite for any crop improvement program. It helps plant breeders in identifying promising lines for possible crosses. Materials and methods: This study was carried out at AfricaRice Center, International Institute of Tropical Agriculture (IITA) Ibadan, Nigeria, and evaluated 123 accessions from South Korea with 7 genotypes form Africa. The experiment was conducted in dry season using Alpha lattice design with 26 blocks each planted in five entries, replicated two times. Results: PCA showed that the first four components accounted for $73.59 \%$ of the total variation. Thus, suggest the presence of large genetic variability, which is of important, as it gives wide spectrum of selection to the breeders. Among all genotypes UPN296, UPN248 and UPN272 showed higher number of productive tillers, while UPN255, UPN332, and UPN 285 were superior for 1000-grain weight. The genotypes such as UPN277 and UPN261 proved to be better for number of spikelets, while UPN347, UPN266, and UPIA2 were better for grain yield. Cluster analysis grouped the 130 genotypes into 4 clusters. All the 17 SSRs markers used were polymorphic. A total of 70 alleles were obtained with an average of 4.12 , and ranged from 2 to 6 . PIC values ranged from 0.34 to 0.76 with an average of 0.53 with 17 SSR markers. UPGMA dendrogram based on similarity index of simple matching grouped 130 genotypes into three clusters. Conclusion. UPN347, UPN277, UPN296, UPN255 and UPIA2 shown to be the most promising genotypes that could be used for rice hybridization, genetic improvement and rice hybrid programme in Nigeria.
\end{abstract}

Keywords: Rice Genotype, Genetic Diversity, PIC, SSR Marker

\section{Introduction}

Rice (Oryza sativa) is the most widely grown and the staple food of an estimated 3.5 billion people worldwide [1] however food insecurity remains a serious global problem. The world population is predicted to reach nine billion by the year 2050 [2], but already by the year 2035, an estimate of $116 \mathrm{Mt}$ of milled rice will be needed worldwide [3] to meet the increasing in demand. In Africa, where rice is the most rapidly growing food, about 30 million tons of rice will be required to feed the population, representing an increase of $130 \%$ in rice consumption from 2010 [4]. In Africa, rice is cultivated in 40 countries on nearly 10 million hectares in rain-fed upland and aquatic ecologies [5]. Although, West Africa has about 4.4 million hectares planted to rice [6], there is a production deficit due to high demand, which surpasses local production. To meet the food demand of the growing population and to achieve food security, the present production level needs to be increased. For a successful breeding program, germplasm evaluation is a pre-requisite on which the future actions could be taken in any crop 
improvement programme.

Molecular markers are one of the tools for genetic resources characterization and grouping into distinct cluster based on genetic distance, thereby increasing the efficiency of breeding [7]. There should be a good understanding of the relationship between genotypic and phenotypic variation, which is key in the application of genomics in plant improvement [8]. Recent techniques, such as DNA-based markers, provide highly effective and reliable tools for evaluating genetic diversity in rice crop germplasm. Simple Sequence Repeat (SSR) is one of the most DNA molecular markers widely used to evaluate the genetic diversity and establishment of unique fingerprint owing to their abundance, codominant inheritance, high polymorphism, reproducibility, ease of assay by (PCR) polymerase chain reaction [9]. SSR markers have been effectively utilized for many purposes in rice production: genetic diversity and relatedness [10], QTL mapping [11], marker assisted selection and rice domestication [12]. With this background, the study was undertaken to assess genetic diversity among Korea lines and Africa adapted rice varieties using morphological traits and molecular markers and identify the promising lines and also, based on cluster analysis for their introgression into the existing rice breeding programme.

\section{Materials and Methods}

\subsection{Genetic Materials and Planting}

One thirty rice genotypes were used for this study under irrigation system. Among the genotypes, 123 were collected from KAFACI in South Korea, three from University of Port Harcourt, one from NCRI and three from AfricaRice-Nigeria (Table 1). Rice seeds were sown in the nursery and $21 \mathrm{~d}$ old seedlings were transplanted into the field. The experiment was laid out in $26 \times 5$ Alpha Lattice Design at $20 \mathrm{~cm} \times 20 \mathrm{~cm}$ spacing in two replications.

Recommended cultural practices such fertilizer application and weeding were adopted. At transplanting day $200 \mathrm{kgha}^{-1}$ of NPK (15-15-15) was applied as basal and $100 \mathrm{kgha}^{-1}$ of Urea in two splits of 65kgha-1 at mid-tillering stage (30 DAP) and 35 kgha-1 at booting stage (45 DAP). Weeds were controlled twice by selective herbicide Oriozol Plus $(300 \mathrm{ml} /$ 20 liters of water) at early stage of crop development and before flowering.

\subsection{DNA extraction and SSR Analysis}

DNA was extracted from the leaves of $25 \mathrm{~d}$ old seedlings according to the CTAB modified method. The obtained DNA was dissolved in $100 \mu \mathrm{l}$ of $1 \mathrm{X}$ TE buffer and stored at $-20^{\circ} \mathrm{C}$, and then diluted to $25 \mathrm{ng} / \mu \mathrm{l}$ using double distilled water to obtain the working solution.

A total of 17 single sequence repeart (SSR) were used to evaluate the polymorphism of 130 genotypes (Table 2). PCR was performed in $10 \mu \mathrm{l}$ reaction mixture volume containing 2 $\mu \mathrm{l}$ of DNA, $6.49 \mu \mathrm{l}$ of sterile $\mathrm{H}_{2} \mathrm{O}, 1 \mu \mathrm{l}$ of $10 \mathrm{X}$ buffer, $0.2 \mu \mathrm{l}$ of dNTPs $(1 \mathrm{mM}), 0.75 \mu \mathrm{l}$ of $\mathrm{MgCl}_{2}(50 \mathrm{mM}), 0.1 \mu \mathrm{l}$ of Taq polymerase, $0.5 \mu \mathrm{l}$ of the Forward primer $(100 \mathrm{mM})$ and 0.5 $\mu \mathrm{l}$ of the Reverse primer $(100 \mathrm{mM})$. Mineral oil was added to the reaction mixture to prevent evaporation. The PCR reaction was performed using a thermal cycler system (96 well alpha-units). The PCR program used consisted of an initial denaturation at $94^{\circ} \mathrm{C}$ for 2 min followed by a series of 35 cycles, each of which consisted of a denaturation at $94^{\circ} \mathrm{C}$ for 30 second, annealing at $55^{\circ} \mathrm{C}$ for 45 second and extension at $72^{\circ} \mathrm{C}$ for 45 second. The program ends with a final elongation of $72^{\circ} \mathrm{C}$ for $2 \mathrm{~min}$. The SSR products were separated on a denaturing $6 \%$ polyacrylamide gel and visualized by silver staining. The electrophoretic bands were scored as 1 (present) or 0 (absent) to form a raw data matrix for further analysis.

Table 1. Rice genotypes used in ths study under irrigation condition from October to March at Africa Rice experiment station-IITA.

\begin{tabular}{|c|c|c|c|c|c|c|}
\hline Sources & Genotype & & & & & \\
\hline \multirow{22}{*}{ South Korea } & UPN334 & UPN339 & UPN238 & UPN289 & UPN237 & UPN307 \\
\hline & UPN335 & UPN343 & UPN280 & UPN248 & UPN274 & UPN249 \\
\hline & UPN346 & UPN316 & UPN227 & UPN326 & UPN328 & UPN243 \\
\hline & UPN315 & UPN234 & UPN268 & UPN311 & UPN327 & UPN347 \\
\hline & UPN348 & UPN259 & UPN246 & UPN245 & UPN239 & UPN336 \\
\hline & UPN230 & UPN296 & UPN275 & UPN231 & UPN341 & UPN294 \\
\hline & UPN349 & UPN288 & UPN272 & UPN251 & UPN266 & UPN340 \\
\hline & UPN241 & UPN287 & UPN308 & UPN233 & UPN309 & UPN269 \\
\hline & UPN271 & UPN333 & UPN244 & UPN320 & UPN312 & UPN293 \\
\hline & UPN270 & UPN319 & UPN262 & UPN317 & UPN282 & UPN229 \\
\hline & UPN304 & UPN276 & UPN279 & UPN247 & UPN323 & UPN345 \\
\hline & UPN252 & UPN292 & UPN314 & UPN281 & UPN299 & UPN232 \\
\hline & UPN290 & UPN286 & UPN325 & UPN329 & UPN295 & UPN344 \\
\hline & UPN264 & UPN321 & UPN297 & UPN310 & UPN322 & UPN260 \\
\hline & UPN250 & UPN261 & UPN240 & UPN267 & UPN324 & UPN285 \\
\hline & UPN306 & UPN300 & UPN332 & UPN253 & UPN337 & UPN273 \\
\hline & UPN228 & UPN331 & UPN306 & UPN300 & UPN332 & UPN253 \\
\hline & UPN330 & UPN255 & UPN277 & UPN247 & UPN235 & UPN284 \\
\hline & UPN283 & UPN291 & UPN242 & UPN258 & UPN342 & UPN256 \\
\hline & UPN265 & UPN303 & UPN278 & UPN301 & UPN305 & UPN338 \\
\hline & UPN313 & UPN257 & UPN298 & UPN337 & UPN273 & UPN228 \\
\hline & UPN301 & UPN305 & UPN265 & UPN303 & UPN278 & UPN331 \\
\hline
\end{tabular}




\begin{tabular}{lllll}
\hline Sources & Genotypes & & & \\
\hline & UPN236 & UPN263 & UPN298 & UPN257 \\
University of Port Harcourt & UPIA3 & UPIA2 & UPIA1 & \\
Africa Rice & SAHEL210 & SAHEL134 & & \\
NCRI & FARO44 & & & \\
Africa Rice-Benin & ARICA3 & & & \\
\hline
\end{tabular}

\subsection{Data Analysis}

Analysis of variance for each character was done by using genotypes as random effects and replication as fixed effect using the Mixed Procedure "proc mixed" in SAS system for windows version 9.2. Genetic parameters were estimated to identify genetic variation among accessions and to determine genetic and environmental effects on various characters. These genetic parameters were calculated $[13,14]$.

Genotypic variance

$$
\theta \mathrm{g}^{2}=(\mathrm{MSG}-\mathrm{MSE}) / \mathrm{r}
$$

Where MSG is the mean square of genotypes, MSE is mean square of error, and $r$ is number of replications

Phenotypic variance:

$$
\theta_{p}^{2}=\theta_{g}^{2}+\theta_{e}^{2}
$$

Where $\sigma^{2}$ is the genotypic variance and $\sigma_{e}{ }^{2}$ is the mean squares of error.

Genotypic coefficient of variation (GCV) and phenotypic coefficient of variance $(\mathrm{PCV})$ :

$$
\begin{aligned}
& \mathrm{GCV}=\frac{\sqrt{\sigma_{g}^{2}}}{\bar{x}} \times 100 \\
& \mathrm{PCV}=\frac{\sqrt{\sigma_{p}^{2}}}{\bar{x}} \times 100
\end{aligned}
$$

Where $\sigma^{2} \mathrm{~g}=$ Genotypic variance,

$\sigma^{2} \mathrm{p}=$ Phenotypic variance

GCV and PCV values were categorized as low (0 10\%), moderate (10-20\%) and high (20\% and above).

Heritability (Broad sense) was computed manually [15].

$$
\mathrm{H}^{2}=\frac{\sigma^{2} g}{\sigma^{2} P} \times 100
$$

Where $\sigma_{g}{ }^{2}$ is the genotypic variance and $\sigma_{\rho}{ }^{2}$ is the phenotypic variance

The Heritability was categorized as low $(0-30 \%)$, moderate (30-60\%) and high (60\% and above) as [16].

Expected genetic advance (GA):

$$
\mathrm{GA}=\mathrm{k} \times \sigma_{\mathrm{p}} \times \mathrm{H}_{\mathrm{b}}^{2}
$$

Where, $\mathrm{H}_{\mathrm{b}}{ }_{\mathrm{b}}=$ Heritability in broad sense, $\sigma \mathrm{p}=$ Phenotypic standard deviation, $\mathrm{GA}=$ Expected genetic advance and $\mathrm{k}=$ the standardize selection differential at 5\% selection intensity $(\mathrm{K}=2.063)$

Genetic advance expressed as a percentage over mean (GAM) is calculated as:

$$
\mathrm{GAM}=\frac{G A}{\bar{x}} \times 100
$$

Where, GAis the genetic advance and $\bar{x}$ is the general mean of the traits.

Pearson's correlation coefficients were computed to evaluate the relationship among the observed variables and the data analyzed using Unweighted Pair Group Method with Arithmetic Mean (UPGMA) algorithm and dendrogram was constructed based on similarity groups using Ward method [17]. Genetic relationships were also calculated and a dendrogram derived to show the morphological relatedness among genotypes under study. Principal component analysis was performed using correlation matrix to examine the percentage contribution of each trait to total genetic variation by the software SAS version 9.2.'

Powermarker 3.25 was used to calculate number of alleles per locus, major allele frequency, and expected heterozygosity [18]. Polymorphism information content (PIC) was calculated using the following formula [19].

$$
\mathrm{PIC}=1-\Sigma \mathrm{X}_{\mathrm{k}}^{2} / \mathrm{n}
$$

Where: $\mathrm{X}_{\mathrm{k}}^{2}=$ frequency of the $\mathrm{k}^{\text {th }}$ allele in the set of genotypes investigated, $\mathrm{n}=$ number of genotypes.

Table 2. Sequence of primer pairs/markers used in this study during dry season at IITA Bioscience Laboratory.

\begin{tabular}{llll}
\hline Primer name & Forward Primer & Reverse Primer & Tm \\
\hline RM 587 & ACG CGA ACA AAT TAA CAG CC & CTT TGC TAC CAG TAG ATC CAG C & 55 \\
RM 341 & CAA GAA ACC TCA ATC CGA GC & CTC CTC CCG ATC CCA ATC & 55 \\
RM 7000 & CCC TTC TTT TCA ACT GAA TA & TTG TAA CAA TGA ACT CGT TC & TTG AGC CGG AGG TAG TCT TG \\
RM 7389 & AGC GAC GGA TGC ATG ATC & CGC TAC CTC CTT CAC TTA CTA GT & 55 \\
RM 163 & ATC CAT GTG CGC CTT TAT GAG GA & TGA GGA CGA CGA GCA GAT TC & 55 \\
RM 510 & AAC CGG ATT AGT TTC TCG CC & TCG CTA GAT AGG GGA TGT GG & 55 \\
RM 6775 & GCA GAT CAA GTA TGC CTG CC & TGC AAC AGT AGC TGT AGC CG & 55 \\
RM 3183 & GCT CCA CAG AAA AGC AAA GC & GGA GGG AGG AAT GGG TAC AC & 55 \\
RM 1370 & AAA CGA GAA CCA ACC GAC AC & GAC AAA TAT AAG GGC AGT GTG C & 55 \\
RM 340 & GGT AAA TGG ACA ATC CTA TGG C & GCT GGT TTG TTT CAG GTT CG & 55 \\
RM 336 & CTT ACA GAG AA CGG CAT CG & AAC GAG CCA ACG AAG CAG & 55 \\
RM 588 & GTT GCT CTG CCT CAC TCT TG & GGC TAG GAG TTA ACC TCG CG & 55 \\
RM 279 & GCG GGA GAG GGA TCT CCT & & 55 \\
\hline
\end{tabular}




\begin{tabular}{llll}
\hline Primer name & Forward Primer & Reverse Primer & Tm \\
\hline RM 3805 & AGA GGA AGA AGC CAA GGA GG & CAT CAA CGT ACC AAC CAT GG & 55 \\
RM 402 & GAG CCA TGG AAA GAT GCA TG & TCA GCT GGC CTA TGA CAA TG & 55 \\
RM 14001 & TGT GGC TGG GCT CCG ATA CC & ACC CTG CAG GAT CAT CAG AAC G & 55 \\
RM 1369 & AAC CTG AGA GTG CCA ATT GG & TCC CCT ATG AAA GCG GAT TC & 55 \\
\hline
\end{tabular}

Tm - Annealing temperature $\left({ }^{\circ} \mathrm{C}\right)$.

UPGMA dendrogram was constructed based on Neighbor Joining (NJ) method in DARwin 6.0.12 showing genetic relationships among 130 rice genotypes.

\section{Results}

\subsection{PCV, GCV, Genetic Advance and Heritability of Estimated Traits}

The study revealed higher phenotypic variation for all the traits measured than genotypic variance (Table 3 ). The PCV estimates were higher in all traits than the corresponding GCV. The GCV and PCV were low for DM although they were moderate for SpFert and 1000-GrW (Table 3). Low GCV was recorded for PH whereas PCV showed high value for the same traits. Moderate high GCV was observed for $\mathrm{PaW}, \mathrm{NSp}$ and grain yield.

Table 3. Estimates of genetic parameters, broad sense heritability, and genetic advance 12 morphological traits of 130 rices genotypes evaluated at Africa rice/IITA-Ibadan, Nigeria.

\begin{tabular}{|c|c|c|c|c|c|c|c|}
\hline Traits & $\sigma_{g}{ }^{2}$ & $\sigma_{e}{ }^{2}$ & $\sigma_{\rho}^{2}$ & GCV (\%) & PCV (\%) & $H^{2}(\%)$ & GA (\%) \\
\hline DFLW & 65.88 & 10.67 & 76.55 & 8.95 & 9.65 & 86.06 & 17.12 \\
\hline $\mathrm{DM}$ & 96.93 & 5.89 & 102.82 & 8.05 & 8.29 & 94.27 & 16.11 \\
\hline $\mathrm{PH}$ & 96.91 & 375.78 & 472.69 & 9.74 & 21.52 & 19.45 & 8.62 \\
\hline Till & 0.37 & 1.05 & 1.42 & 8.3 & 16.27 & 26.05 & 8.73 \\
\hline PL & 6.68 & 2.87 & 9.55 & 9.94 & 11.88 & 69.94 & 17.12 \\
\hline NPrTill & 0.41 & 0.95 & 1.36 & 9.14 & 16.65 & 30.14 & 10.34 \\
\hline $\mathrm{PaW}$ & 0.4 & 0.56 & 0.96 & 18.17 & 28.15 & 41.66 & 24.16 \\
\hline SpFert (\%) & 7174.00 & 46.49 & 118.23 & 10.66 & 13.69 & 60.67 & 17.1 \\
\hline $\mathrm{NSp}$ & 873.00 & 1770.37 & 2643.37 & 18.87 & 32.85 & 33.02 & 22.34 \\
\hline $1000-\mathrm{GW}$ & 8.44 & 1.43 & 9.87 & 11.62 & 12.55 & 85.51 & 22.13 \\
\hline GY (kg/ha) & 271408.68 & 161042.6 & 432451.3 & 18.24 & 23.02 & 62.76 & 29.76 \\
\hline
\end{tabular}

$\sigma_{g}{ }^{2}=$ genotypic variance; $\sigma_{e}{ }^{2}=$ error variance, $\sigma_{\rho}{ }^{2}=$ Phenotypic variance; GCV-Genotypic coefficient of variation; PCV- Phenotypic coefficient of variation; $\mathrm{H}^{2}$ - Broad sense heritability; GA- Genetic advance; DFLW = Days to flowering, DM = Days to maturity, $\mathrm{PH}=\mathrm{Plant}$ height, $\mathrm{NTill}=\mathrm{No}$ of tillers/plant, $\mathrm{PL}=$ Panicle length, NPrTill $=$ No of productive tillers/plant, $\mathrm{PaW}=$ Panicle weight, Fill $\mathrm{Gr}=$ No of filled grain/spikelets, SpFert $(\%)=\mathrm{Spikelets}$ fertility, NSp $=$ No of spikelets/panicle, $1000 \mathrm{GrW}=1000$ grain weight, $\mathrm{GrY}=$ Grain yield $(\mathrm{kg} / \mathrm{ha})$.

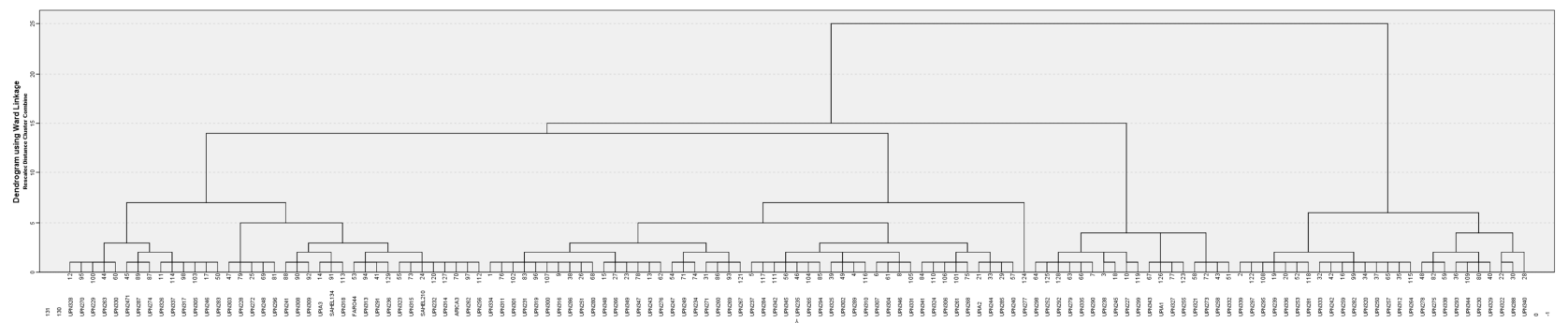

Figure 1. Dendogram using agglomerative clustering method representing distribution of 130 rice genotypes based on morphological traits (from left of the figure is cluster 1 and sub-cluster $1 a$ and $1 b$; cluster 2 and sub-cluster $2 a$ and $2 b$; cluster 3 and cluster 4 and sub-cluster $4 a$ and $4 b$, respectively).

\subsection{Cluster and Principal Components Analysis of Rice Genotypes Evaluated}

Hierarchical cluster analysis of some morphological traits and yield are depicted in the Figure 3. Four main clusters (1, $2,3,4)$ were identified at 12.5 genetic similarity index. Cluster 1 recorded 37 genotypes with 2 sub-clusters: 1a and 1b. Genotypes of cluster 1 had good agronomic traits such as number of productive tiller (UPN296). Cluster 2 had 48 genotypes with two sub-clusters. The major sub-cluster $2 \mathrm{a}$ was differentiated at 5\% genetic similarity index with 47 genotypes, while sub-cluster $2 \mathrm{~b}$ consisted only one genotype (UPN277) which is the most diversified among the genotypes.
Sub-cluster 2a includes genotypes which had characters such as high grain yield (UPN347, UPN266, UPN268 and UPIA2), panicle weight and number of filled grains. Grouping of these genotypes in one cluster indicated their parental relationships. Cluster 3 recorded minimum genotypes (18) which are superior for plant height, 1000-grain weight, panicle length an panicle weight (UPN335, UPN227, UPN327 and UPN332). Cluster 4 consisted 26 genotypes with 2 subclusters. Genotype UPN340 is very short durated and much earlier then the other genotypes.

Principal component analy sis indicates that the first four components accounted for $73.59 \%$ of total variation (Table 4 ). It also revealed that the first principal component accounted 
for $31.12 \%$ of total variance. The second component accounted for $16.20 \%$ of the total variation and featured 1000 -grain weight as the principal trait, followed by days to $50 \%$ flowering $(0.36)$, day to maturity $(0.36)$ and number of spikelets $(-0.35)$ in negative direction. The third principal component accounted for $16.07 \%$ of the total variation and it was loaded mainly by traits such as number of tillers per plant $(0.67)$. The fourth principal component accounted for $10.20 \%$ of the total variance. The variables that contributed negatively are day to $50 \%$ flowering $(-47)$, day to maturity ($0.41)$, number of filled grain $(-0.39)$ and spikelets fertility $(-$ $0.35)$, while panicle length $(0.52)$ contributed positively (Table 4).

Table 4. Eigenvalues, \% variance and cumulative\% variance of 12 morphological traits for the first four principal components.

\begin{tabular}{lllll}
\hline Traits & PC1 & PC2 & PC3 & PC4 \\
\hline Eigen value & 3.73 & 1.94 & 1.92 & 16.07 \\
\%Variance & 31.12 & 16.20 & 63.39 & 10.20 \\
Cumulative variance\% & 31.12 & 47.32 & 0.11 & 73.60 \\
50\% Day to flowering & 0.30 & 0.36 & 0.08 & -0.47 \\
Day to maturity & 0.31 & 0.36 & 0.03 & -0.41 \\
Plant height & 0.39 & 0.22 & 0.67 & 0.25 \\
No. of tillers & -0.05 & -0.00 & -0.05 & 0.14 \\
Panicle Length & 0.26 & 0.08 & 0.68 & 0.52 \\
No. of Prod Till & -0.08 & 0.01 & 0.02 & 0.08 \\
Panicle Weight & 0.44 & -0.10 & 0.03 & -0.35 \\
Spikelets Fertility & 0.17 & -0.25 & -0.00 & -0.39 \\
No. of Filled Grain & 0.39 & -0.41 & -0.05 & 0.22 \\
1000 Grains Weight & 0.19 & 0.48 & 0.29 \\
Grain Yield & 0.17 & -0.24 & 0.07 \\
\hline
\end{tabular}

\subsection{Pearson Correlation Analysis Among Morphological Traits}

The correlation analysis was done on the studied genotypes using SAS software version 9.2 (Table 5). It reveales that days to $50 \%$ flowering showed positive and highly significant correlation with days to maturity and 1000grain weight and positive significant correlation with number of spikelets, spikelets fertility, panicle weight, plant height and yield. Days to maturity was highly significant positively correlated with panicle length. Plant height showed significant correlation with the panicle length. Panicles weight was highly significant positively correlated with number of filled grains. Number tillers per plant was highly significant positively correlated with number of productives tillers (Table 5).

Table 5. Pearson correlation analysis of 12 morphological traits to characterize 130 rice genotypes.

\begin{tabular}{|c|c|c|c|c|c|c|c|c|c|c|c|}
\hline Traits & DFLW & DM & PH & NT & PL & NPT & PW & NFG & SpFert (\%) & NS & 1000-GW \\
\hline $\mathrm{DM}$ & $0.905 * * *$ & & & & & & & & & & \\
\hline $\mathrm{PH}$ & $0.461 * *$ & $0.431 * *$ & & & & & & & & & \\
\hline NT & $0.356 * *$ & $0.409 * *$ & 0.161 & & & & & & & & \\
\hline PL & $0.549 * *$ & $0.682 * * *$ & $0.422 * *$ & $0.272 * *$ & & & & & & & \\
\hline NPT & $0.351 * *$ & $0.391 * *$ & 0.151 & $0.937 * *$ & 0.214 & & & & & & \\
\hline PW & $0.371 * *$ & $0.356^{* *}$ & $0.276 * *$ & 0.165 & $0.381 * *$ & 0.16 & & & & & \\
\hline NFG & $0.271 * *$ & $0.281 * *$ & 0.198 & 0.082 & 0.234 & 0.06 & $0.717 * * *$ & & & & \\
\hline NS & $0.259 * *$ & $0.287 * *$ & 0.191 & 0.094 & 0.228 & 0.055 & $0.656 * * *$ & $0.938 * * *$ & 0.146 & & \\
\hline $1000 \mathrm{GW}$ & $0.628 * * *$ & $0.659 * *$ & $0.385 * *$ & $0.247 * *$ & $0.569 * *$ & $0.240 * *$ & $0.360 * *$ & 0.084 & $0.259 * *$ & 0.124 & \\
\hline GY & $0.285 * *$ & $0.317 * *$ & 0.184 & $0.332 * *$ & $0.311 * *$ & $0.289 * *$ & $0.322 * *$ & $0.333 * *$ & $0.335 * *$ & $0.284 * *$ & 0.172 \\
\hline
\end{tabular}

DFLW $=$ Days to flowering, DM = Days to maturity, PH $=$ Plant height, NT $=$ No of tillers/plant, PL $=$ Panicle length, NPT $=$ No of productive tillers/plant, $\mathrm{PW}=$ Panicle weight, NFG $=$ No of filled grain/spikelets, SpFert $(\%)=$ Spikelets fertility, NS $=$ No of spikelets/panicle, $1000 \mathrm{GW}=1000$ grain weight, GY $=$ Grain yield $(\mathrm{kg} / \mathrm{ha})$.

Highly significant positive correlation with panicles weight and number of filled grain per panicle while nonsignificant positive correlation with spikelet fertility and number of spikelets. Yield showed significant positive correlation with all the studied traits except plant height and 1000-grain weight. (Table 5)

\subsection{Genotyping Using SSR Molecular Markers}

Total of 17 SSR primers were found to be polymorphic (Figure 2) and 70 alleles were identified. The number of alleles ranged from 2 (RM587) to 6 (RM336) with an average of 4.12 alleles per primer (Table 6 and Figure 2).

Genetic diversity: The highest level of gene diversity value (0.79) was observed in loci RM336, and RM588, and the lowest level of gene diversity value $(0.31)$ was observed in loci RM3183 with a mean diversity of 0.58 (Table 6 and Figure 2). The genetic diversity of each SSR marker appeared to be associated with the number of alleles detected.

PIC values: As a measure of the informativeness of each marker, PIC value ranged from a low of 0.26 (RM31830) to a high of 0.76 (RM336, RM588) with a average of 0.53 (Table 
6 and Figure 2). The average heterozygosity value (0.08) is very low as expected for self-pollinated crop.
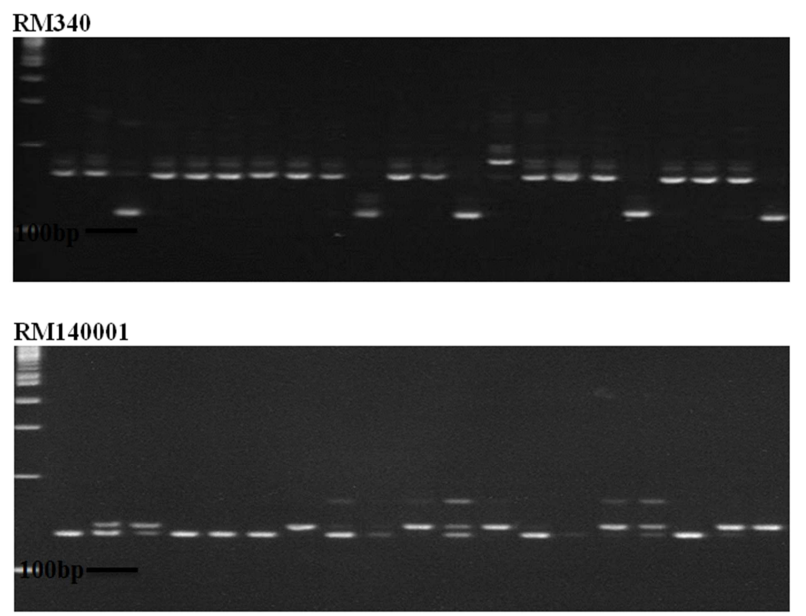

Figure 2. Allelic variations of some rice genotypes generated by SSR markers RM340 and RM 14001 observed on 6\% PAGE. M: 100 bp DNA ladder.

Table 6. Data on major allele frequency, allele number, gene diversity, heterozygosity and PIC obtained among 130 rice genotypes for 17 SSR markers.

\begin{tabular}{llllll}
\hline SSR Markers & Ma & Na & GD & He & PIC \\
\hline RM340 & 0.72 & 5 & 0.45 & 0.05 & 0.42 \\
RM336 & 0.25 & 6 & 0.79 & 0.07 & 0.76 \\
RM341 & 0.34 & 5 & 0.73 & 0.14 & 0.68 \\
\hline
\end{tabular}

\begin{tabular}{llllll}
\hline SSR Markers & Ma & Na & GD & He & PIC \\
\hline RM1369 & 0.51 & 5 & 0.62 & 0.06 & 0.56 \\
RM163 & 0.5 & 5 & 0.68 & 0.06 & 0.64 \\
RM279 & 0.7 & 4 & 0.45 & 0.04 & 0.39 \\
RM402 & 0.52 & 3 & 0.51 & 0.04 & 0.39 \\
RM510 & 0.68 & 3 & 0.44 & 0.09 & 0.35 \\
RM587 & 0.68 & 2 & 0.43 & 0.17 & 0.34 \\
RM588 & 0.28 & 6 & 0.79 & 0.12 & 0.76 \\
RM1370 & 0.75 & 3 & 0.39 & 0.07 & 0.35 \\
RM3183 & 0.81 & 2 & 0.31 & 0.11 & 0.26 \\
RM6775 & 0.56 & 3 & 0.55 & 0.13 & 0.45 \\
RM7000 & 0.3 & 5 & 0.77 & 0.05 & 0.74 \\
RM7389 & 0.47 & 3 & 0.62 & 0.03 & 0.54 \\
RM3805 & 0.51 & 5 & 0.66 & 0.11 & 0.62 \\
RM14001 & 0.31 & 5 & 0.74 & 0.08 & 0.69 \\
Mean & 0.52 & 4.12 & 0.58 & 0.08 & 0.53 \\
\hline
\end{tabular}

\subsection{Clustering of Genotypes Found in Molecular Diversity Analysis}

The genetic distance among rice germplasm led to the construction of Neighbor-Joining (NJ) tree as shown in Figure 3 . The dendrogram revealed three main clusters $(1,2$, 3 ) in the rice genotypes studied at 51.8 genetic similarity index. Cluster 1 comprised 34 genotypes with only one African line (UPIA1) among Korea accessions. Cluster 2 consisted of 29 genotypes while cluster 3 had 57 genotypes, with 3 sub-clusters $3 \mathrm{a}, 3 \mathrm{~b}$ and $3 \mathrm{c}$. The cluster $3 \mathrm{a}$ and cluster 2 comprised only Korea lines, while clusters 1 and sub-cluster $3 \mathrm{~b}$ and $3 \mathrm{c}$ are mixture of Korea lines and African adapted varieties (Figure 3)

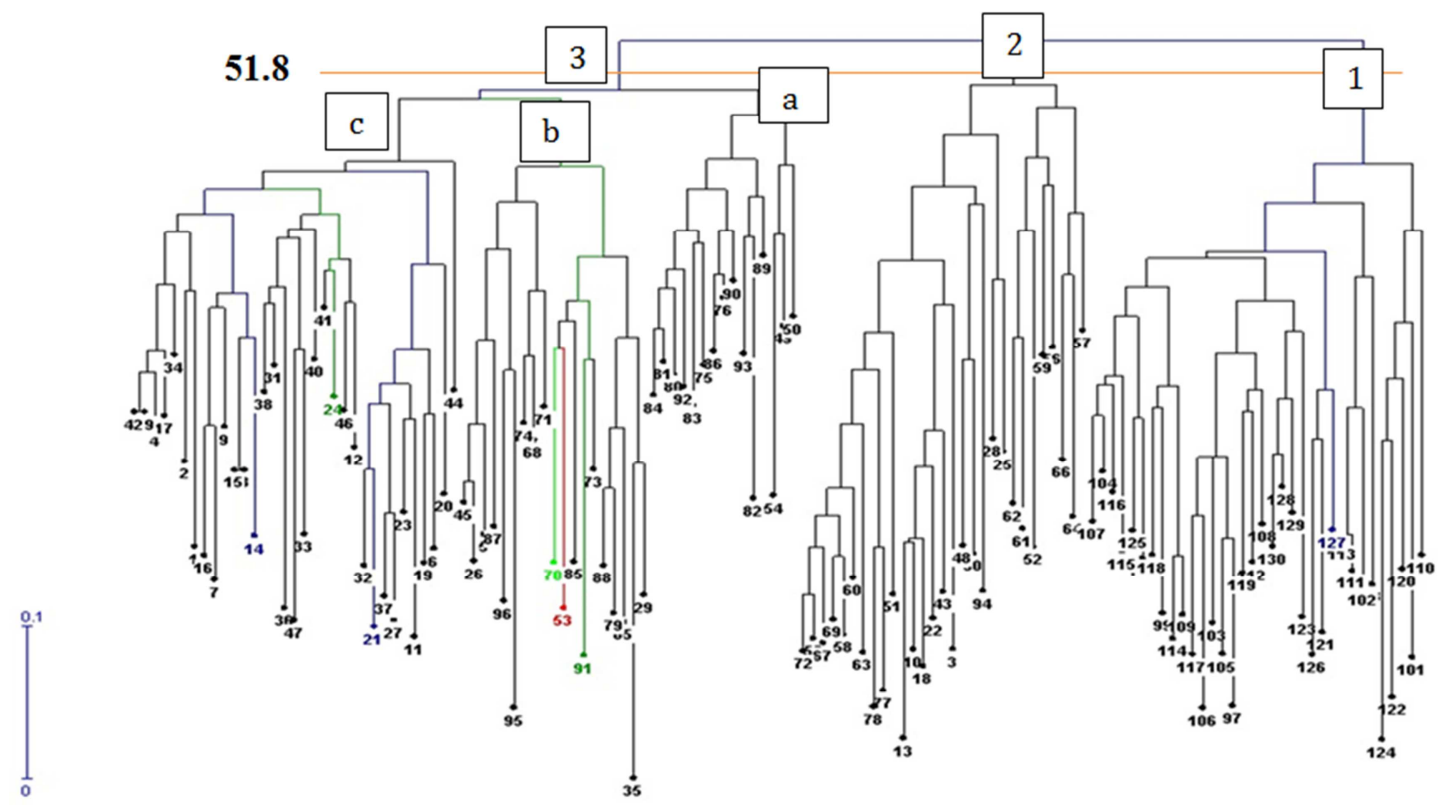

Figure 3. UPGMA dendogram based on Nei's (1972) genetic distance, summarizing the data on differentiation among 130 rice genotypes according to SSRs marker analysis.

\section{Discussion}

\subsection{PCV, GCV, Genetic Advance and Heritability of Estimated Traits}

Phenotypic coefficients of variation (PCV) and genotypic coefficients of variation (GCV) were categorized as low (0$10 \%)$, moderate $(10-20 \%)$ and high $(>20 \%)$ as indicated by Sivasubramanian and Madhavamenon, (2012). Therefore, high PCV was recorded for number of spikelets, number of filled grains, panicle weight, grain yield and plant height and moderate GCV for number of filled grains, number of 
spikelets, grain yield and panicle weigh, which suggests the possibility of improving this trait through hybridization to create variation before selection. The estimates of GCV and PCV were low in the present study for days to maturity $(8.05 \%, 8.29 \%)$. Similar findings were reported [20]. In general, a high coefficient of variability indicates good level of selection and improvement of these traits. Low values indicate the need for creation of variability either by hybridization or mutation followed by selection [21].

The magnitude of phenotypic coefficient of variation (PCV) estimates in the present study was found to be slightly higher than their respective genotypic coefficient of variations (GCV) for all the studied characters which might be due to environmental factors in rice $[22,23]$. However, the narrow magnitude of difference between phenotypic and genotypic coefficients of variations were recorded for characters such as days to maturity, plant height, and panicle length indicating limited influence of environment in the expression of these characters. These results corroborate with [24], thus, selection based on phenotypic performance of these characters would be effective to bring about considerable genetic improvement. Therefore, the rice breeders may make superior genotypes selection based on phenotypic performance for these traits. High heritability in the broad sense recorded for day to maturity, days to $50 \%$ flowering, 1000 grain weight, panicles length and grain yield shows that these traits can be easily selected phenotypically in the field during a breeding programme. Panicles weight, number of filled grains, number of spikelets and number of productive tillers had medium heritability estimates, which indicates that improvement can be made through simple selection. In contrast, plant height, number of tillers and number of productive tillers had low heritability which indicates greater influence of environment on the expression of the characters, direct selection for these traits may not be effective. Therefore, methods of selection based on progeny testing and families are more effective and efficient. Similar results were also reported by other researchers in rice [23, 25, 26] for number of productive tillers per plant. Knowledge of genotypic coefficient of variations coupled with heritability estimates and genetic advance could be most useful. Genetic Advance (GA) ranged from $8.62 \%$ for plant height at maturity to $29.76 \%$ for yield. This suggests that genetic improvement of these traits can be achieved through mass selection [27]. Traits such as plant height, tiller number, and number of spikelets which exhibited low heritability estimates, are likely to be more influenced by the environment and selection by progeny testing or in segregating population could be preferred. High heritability estimates and genetic advance had been earlier reported in crops $[28,29,30]$. Previous studies suggested that high broad sense heritability; PCV and GCV for yield and yield related traits are good predictors for high grain yield in crops [31].

\subsection{Cluster and Principal Component Analysis}

Dendrogram constructed on the Euclidian distance matrix using Ward's linkage method grouped the 130 lines of rice into four clusters at genetic dissimilarity level of 12.5 (Figure 3.). Cluster analysis provided with a complete view of genetic variation among 130 genotypes. This is a useful tool in a hand of the plant breeders for the genetic improvement of rice. Sub-cluster $1 \mathrm{~b}, 2 \mathrm{a}$ and cluster 3 are composed of Korea and African lines; however sub-cluster 1a, 2b and cluster 4 consists only of Korea lines. If we select one genotype from each cluster then UPN296, UPN347, UPN277, UPN332 and UPN340 could be selected from cluster 1, cluster $2 \mathrm{a}$, cluster $2 \mathrm{~b}$, cluster 3 and cluster 4 respectively for breeding poposes. For future breeding program, parents are selected from diverged clusters with better agronomic performance or from each cluster one parent is selected and then the selected genotypes are subjected to crossing therefore, UPN340 could be useful in breeding for shorten duration rice [32],

Principal Components Analysis (PCA) explained the genetic variation among the genotypes for all agromorphological traits under study. Data was considered in each component with Eigenvalues more than 1, which determines as a minimum $10 \%$ of the variation [33]. Superior Eigenvalues are considered as best attributes in principal components. In our study four principal axis exhibited Eigenvalues of $>1$ and showed cumulative variation of $73.59 \%$. It indicates that the identified characters within these components showed immense influence on the phenotype of the genotypes.

PCA explained the genetic diversity of the rice germplasm. It assesses the importance and the contribution of each coefficient of correct vectors indicates the degree of contribution of every original character with each principal component is correlated and that the higher the coefficients, the more effective they will be in discriminating between germplasm, regardless of the positive or negative sign. [34, 35] In this present study variation did exist among 130 rice genotypes with respect to the 12 traits that were evaluated, forinstance, in PC4 (Principal Component 4), panicle length, $50 \%$ days to flowering and day to maturity and panicle length in PC4 and PC4 in grain yield and other related traits $[36,37]$. The PC1 (Principal Component 1) consisted of plant eight, panicle weight, number of filled grains, and number of spikelets, this corroborate [38]. Principal component analysis revealed that PC1 and PC2 were dominated by yield related traits viz. 1000-grain weight, panicle length, plant height, panicle weight, spikelet fertility, number of spikelets. These traits are considered as the most important for classifying the variation existing in the germplasms. Therefore, intensive selection procedures could be designed to bring about quick improvement of dependent variable such as grain yield by choosing lines from PC1 and PC2. Recent report indicated that in PC2 plant height had high weight and factor loading, thus indicates that PC2 represents latent variables for morphological traits and characters with high variability are expected to provide high level of gene transfer during breeding programs [39-41]. 


\subsection{Correlation Analysis}

The relationships existing between 12 quantitative traits as shown by correlation coefficients (Table 3 ). Grain yield was positively correlated with panicle weight, spikelets fertility, number of spikelets per panicle, panicle length, number of tillers per plant, number of productive tillers per plant and number of filled grain. The degree of association among characters is an important factor when dealing with a complex trait such as yield that is controlled by many genes and highly influenced by the environment [42]. The significant positive correlations between yield and some of the traits indications that selection in favour of these traits could lead to positive indirect selection for grain yield improvement. High positive association was observed between 1000-grain weight and rice grain yield. Also, high positive correlation was reported between plant height, productive tillers per plant and grain yield [39, 43].

\subsection{Genotyping Using SSR Molecular Markers and Clustering of the Genotypes}

All the 17 SSRs primers were found to be polymorphic (photo 1) and 70 alleles were identified. The frequency of major allele at each locus varied from 0.25 to 0.81 with average of 0.52 . The number of alleles ranged from 2 (RM587) to 6 (RM336) with an average of 4.12 alleles per primer (Table 6), this number is similar to the average value of 4.3 alleles per locus and found up to 203 alleles for 48 SSR among 11 Venezuelan rice cultivars, thus indicates markers used were less polymorphic as compared to this study [44].

Furthermore, the average value (4.12) of alleles per locus obtained was higher than the values reported in previous studies [44, 45]. In this study, maximum number of polymorphic alleles (6) was obtained with the marker RM336 and RM588, while the minimum number of polymorphic alleles (2) was obtained with RM587 and the average heterozygosity value $(0.08)$ is very low as expected for selfpollinated crop as rice.

PIC value is a reflection of allele diversity and frequency among the genotypes. It was calculated for each locus to evaluate the information of each marker. In this study, PIC value ranged from 0.26 (RM3183) to 0.76 (RM336) with a mean of 0.53 were obtained. The highest PIC value 0.76 was obtained for RM336 and RM588 followed respectively by RM7000 (0.74) and RM14001 (0.69). The primers RM336 and RM588 were considered as the best markers.

Markers with a PIC value of 0.5 or higher indicate that they are highly informative and extremely useful in distinguish the polymorphism rate of a marker at a specific locus [46]. The PIC value found in this study is similar to previous $[47,48]$. Though, PIC value lower than 0.5 this may hide information carried by gene at a specific locus [45, 49]. The genetic diversity of each SSR marker appeared to be associated with the number of alleles detected per locus that is the higher PIC value of a locus, the higher the number of alleles detected [50].

\subsection{Clustering of Genotypes Found in Molecular Diversity Analysis}

Similarities were observed in morphological and moleculaer clustering of the genotypes evalauated. The genetic distance among rice germplasm led to the construction of Neighbor-Joining (NJ) tree as depicted in Figure 2. The dendrogram revealed three main clusters $(1,2$, 3 ) in the rice genotypes studied at 51.8 genetic similarity. Basically, crossing of genotypes of the same cluster may not to give superior hybrids or segregants, because of the little divergence that will be observed among them. However, a larger divergence will generate high amount of heterosis in F1 and subsequent generations. Cluster 1 comprised 34 genotypes with only one African line (UPIA1) among Korea accessions. Cluster 2 consisted of 29 genotypes all Korea, and cluster 3 , the maximum with 67 genotypes. It divided into 3 sub-clusters $3 \mathrm{a}, 3 \mathrm{~b}$ and $3 \mathrm{c}$. Cluster $3 \mathrm{a}$ comprised of only Korea lines, while clusters $3 b$ and $3 c$ are mixtures of Korea lines and African adapted varieties, thus crosses between clusters could create higher heterosis than the parentallnes. The dendrogram showed that African adapted varieties were closely related to some of Korea lines belonging to the same cluster, while UPIA1 belonging to different cluster suggesting that these variety is genetically diverse in origin. This may be of help to rice breeders in the selection of parental lines for further hybridization and genetic improvement.

\section{Conclusion}

Results revealed that PCV was higher than GCV for all the traits under studied, which could be due to environmental factors for the expression of these characters. Breeders should take this into consideration when setting a breeding programme for yield improvement. Yield was positive significant correlated with all traits under studied except plant height ant 1000-grain weight. The first four components of PCA accounted for $73.59 \%$ of total variation giving an estimation of the relative contribution of various traits to the genotypes under studied. The genotypes were grouped into three main group for molecular and four for morphology dendrogram. Crosses between these divergent clusters may to produce high heterosis in F1 generation. The PIC values ranged from a low of 0.26 (RM3183) to a high of 0.76 (RM336, RM588) and averaged 0.53 indicating highly informative and extremely useful in distinguish the polymorphism rate of a marker at a specific locus. High genetic diversity observed between cluster 1 and cluster 3 indicate that genotypes from cluster 1 in association with those from cluster 3 could be good candidate in breeding programme for genetic improvement. These genotypes UPN347, UPN277, UPN296, UPN255 and UPIA2 shown to be the most promising genotypes that could be used for rice hybridization, genetic improvement and rice hybrid programme. UPN340 could be used in breeding for shorten duration rice variety. 


\section{References}

[1] Muthayya, S., Sugimoto, J. D., Montgomery, S., \& Maberly, G. F. (2014). An overview of global rice production, supply, trade, and consumption. Annals Of The New York Academy Of Sciences, 7-14. Https://doi.org/10.1111/nyas.12540.

[2] Alexandrotos, N. and Bruinsma J. (2012). World agriculture towards 2030/2050: The 2012 revision. Food and Agriculture Organisation, Rome. ESA Working Paper No. 12-03.

[3] Seck, P. A., Diagne, A. Mohanty, S. and Wopereis, M. C. S (2012) Crops that feed the world 7: rice. Food Security 4 (1): $7-24$.

[4] El-Namaky, R., Coulibaly, M. M. B., Alhassan, M., Traore, K., Nwilene, F., Dieng I., Manneh, B. (2017). Putting plant genetic diversity and variability at work for breeding: Hybrid rice suitability in West Africa. Diversity Mdpi, 9 (3): 1-12. Https://doi.org/10.3390/d9030027.

[5] Negussie, Z., Kalimuthu, S. and Moussa, Sie (2017). Rice production in Africa. In: Rice production worldwide. Springer chapter 5: 117-135. DOI https://doi.org/10.1007/978-3-31947516-5 5 .

[6] Somado, E. A., Guei, R. G. and Keya, S. O. (Ed) (2008). "NERICA: The New Rice for Africa a compendium". Availlable at https://www.warda.org/publication/nericacomp/Nerica\%20 Compendium.pdf. Accessed 15/11/2018.

[7] Moose, S. P., and Mumm (2008) Molecular plant breeding as the foundation for $21^{\text {st }}$ century crop improvement. Plant physiology, 147 (3): 969-977.

[8] McCouch, S. R., Wing, A., Venuprasad, M. S. R., Gary, A., E. M. Sorrels and J. L. Jannick (2013) Making rice genomic work for africa. CAB International. Realizing Africa's Rice Promises. 108-129.

[9] Chen, C., HeW., Yacouba, T., Nsabiyumva, A., Dong, X., Mawunyo, Y., Jin, D.(2017). Molecular characterization and genetic diversity of different genotypes of Oryza sativa and Oryza glaberrima. Electronic Journal of Biotechnology, 30: 48-57. Https://doi.org/10.1016/j.ejbt.2017.08.001.

[10] Pervaiz, Z. H., Rabbani, M. A., Khaliq, I., Pearce, S. R., Malik, S. A. (2010). Genetic diversity associated with agronomic traits using microsatellite markers in Pakistani rice landraces. Electronic Journal of Biotechnology, 13: 4-5.

[11] Guo, Y., Cheng, B., Hong, D. (2010). Construction of SSR linkage map and analysis of QTLs for rolled leaf in Japonica Rice. Rice Science, (17): 28-34.

[12] Sweeney M, McCouch S. (2007). The complex history of the domestication of rice. Annals of Botany; 100: 951- 957. PMID: 17617555 .

[13] Burton GW, Devane EH (1953) Estimating heritability in tall fescue (Festuca arundinacea) from replicated clonal material. Agronomy Journal 45: 478-481.

[14] Johnson HW, Robinson HF, Comstock RE (1955) Estimates of genetic and environmental variability in soybeans. Agronomy journal 47: 314-318.

[15] Allard, R. W. (1960). Principles of Plant Breeding. John Wiley and Son Inc., New York, USA. 485.
[16] Robinson HF, Comstock RE, Harvey PH (1949) Estimates of heritability and the degree of dominance in corn. Agronomy Journal 41 (8): 353-359.

[17] Ward, J. H. J. (1963). Hierarchical grouping to optimize an objective function. Journal of the American Statistical Association, 58 (301): 236-244.

[18] Liu, K. \& S. V. Muse (2005). Power Marker Integrated Analysis Environment for Genetic Marker Data. Bioinformatics (21): 2128-2129, https://doi.org/10.1093/bioinformatics/bti282.

[19] Botstein, D. R. L., White, M. Skolnick, R. W., Davis (1980). Construction of a genetic linkage map in man using restriction fragment length Polymorphism. American Journal of Human Genetics. 32: 314-331.

[20] Pandey VR, Singh PK, Verma OP, Pandey P. (2012) Interrelationship and path coefficient estimation in rice under salt stress environment. International Journal of Agricultural Research 7: 169-184.

[21] Tiwari DK, Pandey P, Tripathi S, Giri SP, Dwivedi JL (2011) Studies on genetic variability for yield components in rice (Oryza sativa L.). 3: 76-81.

[22] Ogunbayo SA, Ojo DK, Sanni KA, Akinwale MG, Toulou B.(2014) Genetic variation and heritability of yield and related traits in promising rice genotypes (Oryza sativa L.). Journal of Plant Breeding and Crop Science 6: 153-159.

[23] Idris AE, Justin FJ, Degas YMI, Abuali AI (2012) Genetic variability and inter relationship between yield and yield components in some rice genotypes. American Journal of Experimental Agriculture 2: 233-239.

[24] Abebe, T., Sentayehu A. and T. Leta (2017). Genetic variability, heritability and genetic Advance for yield and its related traits in rainfed lowland Rice (Oryza sativa L.) Genotypes Advanced in Crop Science and Technology, 5 (2): 45-59. Https://doi.org/10.4172/2329-8863.1000272.

[25] Fentie D, Alemayehu G, Siddalingaiah M, Tadesse T (2014) Genetic variability, heritability and correlation coefficient analysis for yield and yield component traits in upland rice (Oryza sativa L.). East African Journal of Science 8: 147-154.

[26] Akinwale MG, Gregorio G, Nwilene F, Akinyele BO, Ogunbayo SA, et al. (2011) Heritability and correlation coefficient analysis for yield and its components in rice (Oryza sativa L.). African Journal of Plant Science 5: 207-212.

[27] Ibrahim MM, Hussein RM, (2006) Variability, heritability and genetic advance in some genotypes of roselle (Hibiscus sabdariffa L.) World Journal of Agricultural Science. 2: 340345.

[28] Li W, Song TM. (1991). Estimates of genetic parameters for 13 quantitative traits in a recombined high oil maize population of IHO [(80) x Alexo (C23)]. Acta Agronomica Sinica. 17: 470-475, https://doi.org/10.1093/bioinformatics/bti282.

[29] Jha PB, Ghosh J. (1998). Genetic variability in fodder maize. Journal of Research, Birsa Agricultural University. 10: 139143.

[30] Singh JM, Dash B. (2000). Analysis of genetic variability and character association in maize. African Crop Science Journal. 5: $1-8$. 
[31] Murtadha S, Ariyo OJ, Kehinde OB. (2004). Character association of seed yield and its components in okra [Abelmoschus esculentus (L.) Moench]. Ogun Journal of Agricultural Science. 3: 222-233.

[32] Choudhury, P. and P. Das, (1997). Genetic variability, correlation and path analysis in deep water rice. Journal of Agriculture and. Science Social. 10: 155-157.

[33] Brejda, J. J., Moorman, T. B., Karlen, D. L., Dao, T. H. (2000) Identification of regional soil quality factors and indicators in Central and Southern High-Plains. Soil Science Social of America Journal (64): 2115-2124.

[34] Kumar A. Pachauri, AK Sarawgi, S. Bhandarkar and G. C. Ojha (2017). Agro-morphological characterization and morphological based genetic diversity analysis of Rice (Oryza sativa L.) germplasm. Journal of Pharmacognosy and Phytochemistry; 6 (6): 75-80.

[35] Nachimuthu VV, Robin S, Sudhakar D, Raveendran M, Rajeswari S, Manonmani S. (2014). Evaluation of rice genetic diversity and variability in a population panel by principal component analysis. Indian journal of science and technology. 7 (10): 1555-1562.

[36] Gour. L, S. B. Maurya, G. K. Koutu, S. K. Singh, S. S. Shukla and D. K. Mishra (2017). Characterization of rice (Oryza sativa L.) genotypes using principal component analysis including scree plot \& rotated component matrix. International Journal of Chemical Studies. 5 (4): 975-983.

[37] Sohgaura N, Mishra DK, Koutu GK, Singh SK, Kumar V, Singh P. (2015). Evaluation of high yielding and better quality rice varieties using principal component analysis. Ecology. Environment \& Conservation. (21): 187-195.

[38] Kumar, V, Koutu G. K., Singh S. K, Mishra D. K, Singh P. K, Sohgaura N. (2014). Genetic analysis of inter sub-specific derived mapping population (RILS) for various yield and quality attributing traits in rice. International science journal (Peer-reviewed), 1 (3): 1-7.

[39] Andrew Abiodun Efisue, Ella Elizabeth Igoma. Screening Oryza Sativa L. for Salinity Tolerance during Vegetative Stage for the Coastal Region of Niger-Delta Nigeria. Journal of Plant Sciences. Vol. 7, No. 1, 2019, pp. 21-26. doi: 10.11648/j.jps.20190701.14.

[40] Gana, A. S. (2006). Variability studies of the response of rice varieties to biotic and abiotic stresses. Dissertation for Award of PhD Degree at Ilorin University: 187.
[41] Aliyu, B., M. O. Akoroda, and Padulosi, S. (2000). Variation within Vigna reticulate. Nigeria Journal of Genetic: 15: 1-8.

[42] Steel R. G. B, Torrie J. H. Principles and proceeders of statistics; 1980. (481 pp).

[43] Sabesan, T. R. Suresh and K. Saravanan. (2009). Genetic variability and correlation for yield and grain quality characters of rice grown in costal saline low of Tamilnadu. Electronic Journal of Plant Breding. (1): 56-59.

[44] Sajib A. M, M. M Hossain, A. T. M. J Mosnaz, H. Hossain, MM Islam, M. S Ali and SH Prodhan, (2012). SSR markerbased molecular characterization and genetic diversity analysis of aromatic landraces of rice (Oryza sativa L.). Journal of Bioscience and Biotechnology (1): 107-116.

[45] Krupa, K. N., Shashidar, H. E., Ningaraj Dalawai, Mahendra Reddy and Vijaykumara Swamy, H. V. (2017). Molecular Marker Based Genetic Diversity Analysis in Rice Geotypes (O. sativa L.) using SSR Markers. International Journal of Pure and Applied Bioscience. 5 (2): 668-678.

[46] DeWoody, J. A., Honeycutt, R. L. and Skow, L. C. (1995). Microsatellite markers in white tailed deer. Journal of Heredity, (86): 317-319.

[47] Lapitan V. C., D. S. Brar, T. Abe and E. D., Redona, (2007). Assesment of genetic diversity of Philippine rice cultivars carrying good quality traits using SSR markers. Breeding Science, (57): 263-270.

[48] Shailesh D. Kumbhar, Pawan L. Kulwal, Jagannath V. Patil, Chandrakant D. Sarawate, Anil P. Gaikwad, and Ashok S. Jadhav, (2015). Genetic diversity and population structure in landraces and improved rice varieties from India, Rice science, 22 (3): 99-107.

[49] Hoque A. Begum. S. N. and L. Hassan. (2014). Genetic diversity assessment of rice (Oryza sativa L.) germplasm unsing SSR markers. Research Agricutural; livestock Fish. 1 (1): $37-46$.

[50] Yu, S. B., Xu, W. J., Vijayakumar, C. H, Ali, J., Fu, B. Y., Xu, J. L., Jiang, Marghirang, R. Domingo, J., Aquino, C., Virmani, S. S. and Li, Z. K.(2003). Molecular diversity and multilocus organisation of the parental lines used in the International Rice Molecular Breeding Program. Theoretical and Applied Genetics, 108 (1): 131-140. 